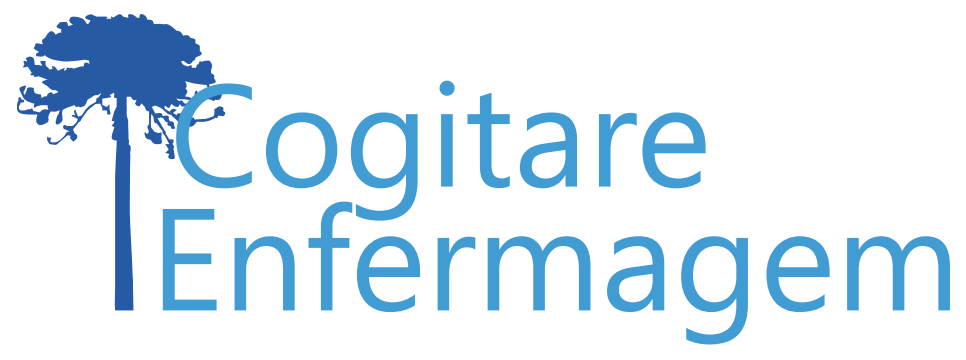

\title{
CONTEXTO DA VIOLÊNCIA CONJUGAL EM TEMPOS DE MARIA DA PENHA: UM ESTUDO EM GROUNDED THEORY*
}

Jordana Brock Carneiro1, Nadirlene Pereira Gomes², Luana Moura Campos³, Nildete Pereira Gomes $^{4}$, Kamylla Santos da Cunha ${ }^{5}$, lonara da Rocha Virgens ${ }^{6}$, Alacoque Lorenzini Erdmann ${ }^{7}$

\section{RESUMO}

Objetivo: desvelar o contexto da violência conjugal experienciados por mulheres em processo judicial.

Método: pesquisa qualitativa baseada na Grounded Theory, realizado com 29 mulheres em processo judicial por violência conjugal e os nove profissionais que atuam junto a duas Varas de Justiça pela Paz em Casa, na Bahia, Brasil. A coleta dos dados foi realizada no período de janeiro a maio de 2015.

Resultados: em que pese a Lei Maria da Penha, o estudo revela que as relações conjugais das mulheres são permeadas por abusos físicos, sexuais, psicológicos, morais e patrimoniais, inclusive expulsão do lar.

Conclusão: o contexto de violência experienciado na conjugalidade feminina se manifesta de diferentes formas, passíveis de identificação por profissionais de saúde, o que possibilita ação de cuidado à mulher e enfrentamento da problemática.

DESCRITORES: Violência; Violência Contra a Mulher; Enfermagem de Atenção Primária; Saúde Pública; Políticas Públicas de Saúde.

\footnotetext{
*Artigo extraído da dissertação de mestrado "Violência conjugal: compreendendo as expressões e repercussões a partir da Grounded Theory". Universidade Federal da Bahia, 2016.
}

\section{COMO REFERENCIAR ESTE ARTIGO:}

Carneiro JB, Gomes NP, Campos LM, Gomes NP, Virgens IR, Cunha KS da, et al. Contexto da violência conjugal em tempos de Maria da Penha: um estudo em Grounded theory. Cogitare enferm. [Internet]. 2019 [acesso em "colocar data de acesso, dia, mês abreviado e ano"]; 24. Disponível em: http://dx.doi.org/10.5380/ ce.v24i0.59431.

\section{(c) (1)}

Este obra está licenciado com uma Licença Creative Commons Atribuiçãa 4.0 Internacional.

${ }^{1}$ Enfermeira. Doutoranda em Enfermagem. Universidade Federal da Bahia. Salvador, BA, Brasil.

${ }^{2}$ Enfermeira. Doutora em Enfermagem. Docente de Enfermagem da Universidade Federal da Bahia. Salvador, BA, Brasil. 9 ${ }^{3}$ Enfermeira. Doutoranda em Enfermagem. Universidade Federal da Bahia. Salvador, BA, Brasil. ()

${ }^{4}$ Fisioterapeuta. Doutoranda em Enfermagem. Universidade Federal da Bahia. Salvador, BA, Brasil. 0

${ }^{5}$ Enfermeira. Doutoranda em Enfermagem. Universidade Federal de Santa Catarina. Florianópolis, SC, Brasil. 9

${ }^{6}$ Enfermeira. Mestranda em Enfermagem. da Universidade Federal da Bahia. Salvador, BA, Brasil.

${ }^{7}$ Enfermeira. Doutora em Enfermagem. Docente de Enfermagem da Universidade Federal de Santa Catarina. Florianópolis, SC, Brasil. 


\title{
MARITAL VIOLENCE CONTEXT AFTER THE MARIA DA PENHA LAW: A GROUNDED THEORY STUDY
}

\begin{abstract}
Objective: To analyze the context of marital violence experienced by women in legal proceedings.

Methodology: This is a qualitative study based on the grounded theory, conducted with 29 women in legal proceedings for marital violence and nine professionals who work at two Courts for Peace at Home in Bahia, Brazil. Data collection was performed from January to May 2015.

Results: Despite the Maria da Penha Law, the study shows that marital relationships of women are permeated by physical, sexual, psychological, moral and property abuse, with some of them being sent away from home.

Conclusion: Marital violence contexts appear in different ways, which can be identified by health professionals, allowing women's care actions to address the problem.
\end{abstract}

DESCRIPTORS: Violence; Violence Against Women; Primary Care Nursing; Public Health; Public Health Policy.

\section{CONTEXTO DE LA VIOLENCIA CONYUGAL EN TIEMPOS DE MARIA DA PENHA: ESTUDIO EN GROUNDED THEORY}

\author{
RESUMEN: \\ Objetivo: Revelar el contexto de la violencia familiar experimentada por mujeres en proceso \\ judicial. \\ Método: Investigación cualitativa fundamentada en la Grounded Theory, realizado con 29 \\ mujeres en proceso judicial por violencia conyugal y los nueve profesionales que actúan con \\ los dos Tribunales de Justicia por la Paz Hogareña en Bahía, Brasil. Datos recolectados de \\ enero a mayo de 2015. \\ Resultados: A pesar de la Ley Maria da Penha, el estudio revela que las relaciones conyugales \\ de las mujeres están teñidas por abusos físicos, sexuales, psicológicos, morales y patrimoniales, \\ incluyendo la expulsión del hogar. \\ Conclusión: El contexto de violencia experimentado por las mujeres en su vida conyugal se \\ manifiesta de diferentes formas, identificables por los profesionales de salud, permitiendo \\ esto la acción de cuidado a la mujer y el enfrentamiento de la problemática.
}

DESCRIPTORES: Violencia; Violencia contra la Mujer; Enfermería de Atención Primaria; Salud Pública; Políticas Públicas de Salud. 
Apesar da promulgação da Lei Maria da Penha, a violência conjugal persiste como grave problema de saúde pública, com sérias implicações para a saúde feminina. Todavia, os(as) profissionais apresentam dificuldade para o reconhecimento do agravo, comprometendo o direcionamento de ações e cuidados demandados pelas mulheres.

Considerada pandemia, uma em cada três mulheres no mundo experienciaram a violência perpetrada pelo parceiro íntimo, sendo que em alguns países, como Índia e Camboja, esse tipo de violência pode alcançar até $70 \%$ da população feminina ${ }^{(1)}$. Dados brasileiros informam que duas em cada três notificações de violência em serviços de saúde têm as mulheres como vítimas ${ }^{(2)}$.

No sentido de enfrentar tal problemática, foi implantada no Brasil a Lei 11.340/2006, a Lei Maria da Penha, que define violência contra a mulher como toda ação ou omissão ancorada na desigualdade de gêneros, que ocasione dano psicológico, físico ou sexual à mulher, inclusive sua morte ${ }^{(3)}$. Apesar da existência desse mecanismo legal, criado para coibir e prevenir a violência contra a mulher, os números de violência permanecem elevados em nosso país ${ }^{(2)}$ e desencadeiam o adoecimento físico e psicológico das mulheres.

Estudos nacionais e internacionais revelam que essas repercussões para a saúde se apresentam através do medo, ansiedade, depressão, transtorno de stress pós-traumático, dores crônicas, distúrbios gastrointestinais, infecções sexualmente transmissíveis, além de lesões como hematomas, fraturas, lacerações, dentre outras ${ }^{(4-6)}$.

Esse cenário em torno da vida e saúde das mulheres alerta para a necessidade de identificação da violência conjugal por profissionais de saúde. Contudo, pesquisa realizada no contexto da Atenção Primaria à Saúde (APS) sinaliza que nenhuma das profissionais entrevistadas relatou abordagem dessa temática na graduação ou nos diferentes cursos de pós-graduação, realizados ao longo das suas carreiras, comprometendo o lidar com essas situações ${ }^{(7)}$.

Considerando a necessidade dos profissionais de saúde em reconhecer a violência conjugal, agravo de grande magnitude para a vida das mulheres, delineou-se como objetivo de estudo desvelar o contexto da violência conjugal experienciados por mulheres em processo judicial.

\section{MÉTODO}

Trata-se de um estudo qualitativo, fundamentado na Grounded Theory, referencial teórico-metodológico que possibilita compreender fenômenos sociais a partir da realidade e dos significados das relações e interações das pessoas em determinado contexto ${ }^{(8)}$. Vincula-se à pesquisa matriz "Reeducação de homens e mulheres envolvidos em processo criminal: estratégia de enfrentamento da violência conjugal", financiada pela Fundação de Amparo à Pesquisa do Estado da Bahia e apoiado pela Secretaria de Segurança Pública da Bahia.

Os cenários de coleta de dados foram duas Varas de Justiça pela Paz em Casa, localizadas no estado da Bahia, Brasil. Os dados foram coletados no período de janeiro a maio de 2015, por meio de entrevistas abertas e individuais, previamente agendadas via contato telefônico, e, posteriormente, transcritas na íntegra para o processo de sistematização.

Compuseram a amostragem teórica deste estudo participantes distribuídas em dois grupos amostrais. O primeiro grupo, escolhido intencionalmente, foi formado por mulheres em processo judicial junto às Varas de Justiça e teve como critério de inclusão: mulheres com representação judicial por violência conjugal. Excluíram-se mulheres cujo 
estado emocional foi contraindicado pelo serviço psicossocial da Vara de Justiça.

A questão norteadora para este grupo foi: "Fale-me sobre a sua vivência de violência conjugal". Em seguida, outras perguntas foram dirigidas às participantes para o avanço da pesquisa e compreensão do tema investigado, conforme preconiza o método(8). A partir da análise das entrevistas do primeiro grupo amostral, surgiu a hipótese: as mulheres, frente à vivência de violência conjugal, buscam o suporte de profissionais da Rede de Atendimento à Mulher em Situação de Violência. Assim, observou-se a necessidade de dar vozes aos profissionais que atuam em instituições da Rede, compondo estes o segundo grupo amostral.

A amostragem teórica, que integrou 38 participantes, foi composta por 29 mulheres em vivência de violência conjugal, as quais participaram do primeiro grupo amostral (13 da primeira Vara e 16 da segunda) e nove profissionais das Varas (assistente social, psicóloga, promotora, 02 defensoras públicas, 02 conciliadoras e 02 juízas) no segundo grupo.

Salienta-se que o projeto atende aos princípios éticos, sendo aprovado pelo Comitê de Ética e Pesquisa (n. 877.905/2014). Para preservar o anonimato, as entrevistadas foram identificadas pelas letras " $M$ " $e$ " $P$ ", Mulheres e Profissionais respectivamente, seguidas de um algarismo arábico de ordem da entrevista. No caso das mulheres, optou-se por inserir também suas idades.

No processo de sistematização dos dados, respeitou-se o processo de análise comparativa durante todo o percurso, coletando e analisando os dados de forma concomitante. Foram elaborados memorandos e diagramas durante a análise dos dados, que dizem respeito aos registros e insights das pesquisadoras no processo de construção da teoria ${ }^{(8)}$. O programa NVIVO ${ }^{\circledR}$ foi utilizado para organização dos dados durante a fase de análise comparativa e codificação dos dados.

A codificação dos dados ocorreu em três etapas: codificação aberta, axial e seletiva(8). $\mathrm{Na}$ codificação aberta, os conceitos foram identificados e agrupados em categorias, de acordo com suas similaridades. Após, na codificação axial, as categorias e subcategorias foram se relacionando a fim de obter uma explicação mais aprofundada dos dados, por meio de um processo analítico norteado pelo modelo paradigmático de cinco componentes da vertente straussiana: contexto, condição causal, condição interveniente, estratégia e consequência.

Por fim, na etapa da codificação seletiva, as relações e interações entre as categorias foram interligadas em torno de uma categoria central, em que emergiu o fenômeno "Vivenciando a violência conjugal como um processo progressivo e cíclico e suas repercussões para a saúde e o desenvolvimento humano". Considerando que o componente contexto, intitulado "vivenciando a violência conjugal", consiste na especificidade que envolve o fenômeno e que cria circunstâncias para que as pessoas respondam por meio de ações e interações ${ }^{(8)}$, optou-se por aprofundar sua discussão neste estudo, visto que o significado das ações dos participantes promove a compreensão do fenômeno central.

\section{RESULTADOS}

O estudo apontou que as 38 colaboradoras tinham idade entre 25 e 71 anos, com média de 41 anos, e residiam em bairros periféricos da cidade. A maioria se autodeclarou negras (pretas ou pardas), união estável ou casada e com filhos, sendo a média de 1,7 criança por mulher.

O componente "contexto" desvelou a violência experienciada na conjugalidade feminina por meio das seguintes expressões: patrimonial, psicológica, moral, sexual e física. 


\section{VIVENCIANDO VIOLÊNCIA PATRIMONIAL}

As falas sinalizam a vivência de violência patrimonial, expressa através da subtração de bens e documentos pessoais e da privação de recursos que atendessem às necessidades das mulheres, como de alimentação e proteção, sendo relatadas situações de expulsão da própria casa.

Ele ficou uns três meses sem comprar comida para dentro de casa. [...] me colocou várias vezes para fora e eu com o menino pequeno. [...] depois do processo, ele pediu para sair do emprego só para não dar a pensão. (M4, 32 anos)

Ele quebrava as coisas de dentro de casa. [...] rasgou meus documentos. (M22, 31 anos)

O companheiro não dava dinheiro nem para os filhos comerem. [...] quando ela começou a receber o benefício social, foi para o interior com os filhos. (P4)

\section{VIVENCIANDO VIOLÊNCIA PSICOLÓGICA}

As mulheres revelaram um contexto conjugal permeado pela vivência de violência psicológica, que compromete sua saúde mental e autodeterminação. Seguem subcategorias ilustrativas:

\section{Ameaça}

Os dados sinalizam que a relação conjugal das mulheres é permeada por ameaças realizadas pelos cônjuges, que vão desde subtração e/ou destruição de bens e recursos econômicos até agressões físicas severas e/ou assassinato da mulher e filhos.

[...] disse que eu iria apanhar como nunca apanhei na vida, que ia tocar fogo na casa, que não iria me dar pensão e tiraria meu filho de mim. (M4, 32 anos)

Ele disse que tocava fogo em mim, na casa e nos filhos. (M10, 59 anos)

Muitas mulheres permanecem anos na relação de violência, porque são ameaçadas de morte. Por isso, elas têm medo de deixar os companheiros. (P5)

\section{Controle}

As falas sinalizam a condição de submissão das mulheres aos seus cônjuges, que acreditam ter o direito de controlar suas ações. Estas se expressaram através da vigilância constante, restrição do direito de ir e vir, além do isolamento social.

Não tinha amizades. Ele dizia que era para sermos apenas nós dois. [...] ele me deixou dois dias em cárcere privado. Fiquei até sem comer. (M12, 32 anos)

Eu só podia sair com ele. Não podia ir nem para a casa da minha família. [...] ficava me monitorando. Ele não queria que eu trabalhasse, rasgava minha farda. (M14, 49 anos).

Nossa sociedade é patriarcal, machista: a mulher pertence ao homem, ao marido, ao pai e tem de ser submissa, satisfazer-lhes as vontades. (P2)

\section{Humilhação e constrangimento}

No estudo, percebe-se vivência conjugal permeada por insultos e ridicularizações, como a exposição das relações extraconjugais para familiares e amigos. Essas manifestações da violência psicológica acabam por atingir a imagem corporal feminina, comprometendo sua autoestima.

Ele estava sempre me depreciando, me xingando, me humilhando: dizia que eu estava 
gorda, horrível, que eu não ia conseguir namorado. [...] e eu acreditava. (M1, 29 anos)

As pessoas (familiares e amigos) vinham me contar que ele estava com mulheres, que tinha um caso com minha vizinha. [...] ele batia e cuspia em minha cara. (M20, 39 anos)

Ele ficava falando que a mãe passava roupa melhor que ela; que fazia comida mais gostosa. [...] xingava ela de vagabunda e ela incorporava o que ele falava. (P1)

\section{VIVENCIANDO VIOLÊNCIA MORAL}

O discurso das participantes permitiu desvelar que a violência moral é marcada por injúrias e difamação, evidenciadas através dos trechos a seguir:

Eu estava em uma festa familiar, mas ele achava que eu estava com algum homem. [...] dizia que o outro fazia o que queria de mim na cama e eu deixava. (M2, 68 anos)

Ele está me difamando. [...] na rua, fica me chamando de puta, vagabunda. (M13, 52 anos)

Casos de violência moral são os chamados crimes contra a honra. [...] xingamentos com linguajar pejorativo que desqualificam a vítima. (P7)

\section{VIVENCIANDO VIOLÊNCIA SEXUAL}

As falas das participantes remetem ao contexto de violência sexual na conjugalidade. Esta realidade se expressa mais comumente pela realização do ato sexual, ainda que sem o consentimento feminino.

Ele me pegou à força algumas vezes. Já me forçou a fazer sexo anal. É muito desagradável ter relação sexual sem querer: é uma violência física. Não sinto prazer. (M4, 32 anos)

Sofria violência sexual todos os dias. [...] já tive relações três vezes no dia. (M20, 39 anos)

Quase nunca a violência sexual é o motivo da denúncia. Elas só falam se a gente tocar no assunto. Elas não entendem que não precisam se submeter àquilo, nem que é violência. (P4)

\section{VIVENCIANDO VIOLÊNCIA FÍSICA}

As histórias partilhadas apontaram para um relacionamento conjugal marcado pela vivência de agressões físicas, como empurrões, tapas, murros e chutes, inclusive no período gestacional.

Tomei um tapa no rosto. [...] fiquei tonta e meu olho vermelho de sangue. (M3, 71 anos)

Estava grávida quando a gente discutiu e ele me deu um murro na barriga. Foi muita dor! Depois, ele começou a me chutar, empurrar e me bater. (M6, 38 anos)

O que mais presencio aqui é ameaça de morte e violência física: socos, pontapés. (P6)

\section{DISCUSSÃO}

O contexto conjugal vivenciado pelas mulheres em situação de violência é marcado por diversas formas de expressão: patrimonial, psicológica, moral, sexual e física. O abuso patrimonial, desvelado neste estudo, configura-se em condutas de retenção, subtração, 
bem como destruição parcial ou total de seus objetos, documentos pessoais, bens, valores e recursos econômicos, incluindo os destinados a satisfazer suas necessidades ${ }^{(3)}$. Essa pôde ser evidenciada diante a retenção financeira pelo cônjuge ou quando este infringe o pagamento da pensão alimentícia, situação corroborada por outra pesquisa brasileira que revela a forma rotineira nos atrasos e a negação em cumprir com a pensão alimentícia ${ }^{(9)}$.

Importante mencionar que, entre os motivos que dificultam honrar o compromisso da pensão alimentícia, encontram-se as dificuldades financeiras, algumas vezes relacionadas ao desemprego, consequente do estigma da prisão preventiva em homens que respondem processos pela Lei Maria da Penha ${ }^{(10)}$.

Contudo, no Brasil, a conduta de negar o provimento para a subsistência de filhos(as) e cônjuge é tipificada no sistema penal, em seu Artigo 244, visto que coloca em risco a segurança e vida dos dependentes ${ }^{(11)}$. Legislações internacionais também garantem - direito das mulheres e crianças de serem providas de suas necessidades básicas. No Equador, essa alienação é tida como violência econômica, sendo garantido à mulher e à prole o direito a reparação integral dos direitos violados ${ }^{(12)}$.

Para além desses problemas, no contexto de violência patrimonial não é incomum as mulheres serem impedidas de adentrar a sua própria residência ou serem postas para fora, conforme confirma estudo que acrescenta que as mulheres, por possuírem laços familiares e sociais frágeis, encontrarem dificuldades em abrigar-se de forma segura(13). Muitas vezes ainda são privadas de levar pertences como roupas, dinheiro e documentos. Em outras situações fica clara a má intenção do conjugue de apossar-se da casa, construída pelo casal, visto que a expulsão se dá justamente quando finda a construção do imóvel. A situação agrava-se quando a exposição à rua se estende às crianças. Esse contexto expõe mãe e criança a maior vulnerabilidade social e de saúde ${ }^{(14)}$.

Vale salientar que, quando há expulsão de um dos cônjuges da residência ou quando as mulheres decidem sair de casa em decorrência da violência, não se configura abandono do lar, que consiste no afastamento em que não se tem intenção de retornar. A partir de 2006, com a promulgação da Lei 11.340, conhecida como Lei Maria da Penha, as mulheres que saíram ou foram expulsas de suas casas passaram a contar com as medidas protetivas de urgência. Dentre as garantias estabelecidas, encontram-se o direito de retornar ao lar juntamente com os seus dependentes, bem como o afastamento do agressor, o qual deve deixar a residência sem levar consigo bens oriundos da sociedade conjugal(3).

Mesmo após a expedição das medidas protetivas de urgência, muitos homens permanecem coagindo as mulheres. A audácia do homem em ameaçar a vida da vítima após ter sido intimado demonstra recalcitrância no cumprimento da lei e disseminação da cultura de impunidade. Pesquisa realizada em cinco capitais brasileiras com 64 operadores do direito e outros profissionais que atuam na aplicação da Lei Maria da Penha confirma eventos de descumprimento das medidas protetivas de urgência ${ }^{(15)}$.

Essa fragilidade abre precedentes para os homens, apesar de impedidos, continuarem ameaçando e colocando em risco a vida das mulheres ${ }^{(13)}$. Merecem destaque casos veiculados na mídia que retratam o inconformismo de homens com a obrigatoriedade de cumprir com financeiramente com o sustento das(os) filhas(os), levando a atos extremos como o assassinato ${ }^{(11)}$.

Os achados deste estudo também evidenciaram que, além de atemorizar as mulheres, os agressores ameaçam com outras violências, destruir seus bens e de levar os filhos sem a devida decisão judicial. Esse contexto, que permeia o sentir-se ameaçada, desencadeia adoecimento mental da mulher, o qual se manifesta por insônia, medo, choro constante e depressão(5). Além disso, a violência psicológica também se fez presente na vida através da vigilância constante, da limitação do ir e vir e do isolamento social. Essas ações deixam claro o controle sobre os comportamentos e decisões da mulher, comprometendo sua saúde emocional(16).

Outra forma de violência contra a mulher relaciona-se às agressões verbais, tais 
como: constrangimentos, humilhações, insultos, injúrias, difamações e calúnias. Ressaltase que em algumas situações, estas são classificadas como violência moral; em outras, como psicológica. A distinção se dá nos casos de injúria, situação em que a ofensa à honra é dirigida diretamente à mulher; difamação, quando a ofensa à reputação da mulher chega ao conhecimento de terceiros; e a calúnia, que ocorre quando uma pessoa é acusada falsamente de um ato criminoso. Cabe lembrar que a dissociação entre a violência psicológica e moral se fundamenta no Brasil após definição preconizada na Lei Maria da Penha ${ }^{(3)}$.

Na Inglaterra e País de Gales, por exemplo, a violência moral continua sendo identificada como violência psicológica (17). Especificamente sobre a violência moral, o estudo mostra que as mulheres passaram por situações em que foram desonradas publicamente, colocando em questão sua reputação, principalmente relacionada à acusação de adultério. Sabe-se que socialmente se têm percepções diferenciadas com relação à traição para a mulher e o homem. É necessário resgatar que, desde o período imperial no Brasil, há registros que legitimam o adultério como motivo para o assassinato de mulheres.

Com base no Código Civil de 1916, o divórcio não era permitido, pois ia de encontro às leis previstas, as quais se pautavam na herança do Direito Canônico Medieval altamente influenciada pelos preceitos religiosos, que considerava o casamento como indissolúvel, exceto em caso de morte do cônjuge. Importante saber que, embora não fosse permitido o divórcio, era lícito o desquite, assegurando a separação de corpo, mas sem quebra do vínculo matrimonial. Assim, diante da infidelidade por parte das mulheres, não era possível rompimento legal e definitivo do casamento civil. Tal fato legitimou por anos a morte de mulheres, sobretudo sob a alegação de defesa da honra ${ }^{(18)}$.

No entanto, sabe-se que a violência contra a mulher não emana da impossibilidade de divórcio ou desquite, pois ainda permanece alarmante o número de mulheres assassinadas pelos cônjuges após a Lei 11.340(3). Apesar do avançar dos dispositivos éticos e legais, percebe-se a força da cultura machista, arraigada no domínio e valorização masculina em detrimento da inferioridade e subserviência feminina. Nessa seara, quando se trata de adultério, percebe-se por um lado a permissividade ao homem e inclusive sua valorização social em função da infidelidade conjugal, e por outro, a condenação e depreciação feminina, colocando em xeque a honra e a dignidade da mulher.

Diante de relações extraconjugais desveladas no estudo, chamou-nos atenção as situações de ridicularização e humilhação a que as mulheres estiveram expostas devido aos relacionamentos íntimos e públicos de seus cônjuges, inclusive com pessoas de seu convívio social. Considerando o constrangimento que permeia tais exposições e sua interferência direta na autoestima feminina, entendemos tratar-se de violência psicológica. Evidência científica corrobora que a infidelidade masculina representa uma forma de maltrato psicológico à mulher, podendo acarretar sentimentos de inferioridade, medo, raiva, ciúme e desconfiança ${ }^{(13)}$.

Quanto às relações sexuais, as entrevistadas relatam sexo sob coação e/ou uso de força física. Pesquisa realizada na Índia indica que o sexo forçado no casamento é comum, sendo que as mulheres reconhecem que, por não haver lei para esse tipo de violação, a comunhão marital se constitui uma forma de "legalização" dos abusos ${ }^{(19)}$. Tal conduta considera-se estupro marital, caracterizada como violência sexual na constância da união conjugal, praticada pelo seu cônjuge ${ }^{(20)}$.

Sobre isso, onze países no mundo sustentam o estupro marital em suas legislações como direito do homem ${ }^{(21)}$, sendo este tipo de violência já apontada pela legislação brasileira como crime ${ }^{(3)}$. Essa forma de expressão nos remete ao comportamento machista e dominador dos homens e ao entendimento do ato sexual como uma obrigação dentro da relação matrimonial, o que nos permite compreender a dificuldade de mulheres e homens reconhecerem a violência sexual.

Não podemos deixar de pontuar a interface entre violência sexual e física, revelada na fala de M4, que reconhece a violação sexual como uma agressão física ao seu corpo. Estudo 
realizado em Hong Kong, China, com 745 mulheres, mostrou que 75 confessaram uso de força física ou ameaças por parte dos cônjuges para forçá-las a ter relações sexuais e 104 relataram que os cônjuges utilizaram outras formas de coerção que não físicas para chegar a tal objetivo ${ }^{(22)}$.

Cabe ressaltar que, de todas as expressões da violência, apenas aquelas que envolvem lesão corporal não necessitam da oferta da denúncia pela mulher ${ }^{(23)}$. Nas demais formas de violência tipificadas pela Lei Maria da Penha, só haverá andamento no processo jurídico e possibilidade do autor ser punido se a própria ofendida proceder com a representação(3). Importante referir ainda que as marcas causadas pela violência física favorecem o reconhecimento do agravo nos serviços de saúde, embora em algumas situações permaneçam veladas devido a não investigação por parte dos profissionais sobre as causas da lesão e/ou não revelação pelas mulheres ${ }^{(24)}$.

Infelizmente, a prática assistencial à mulher em situação de violência conjugal se dá, prioritariamente, no campo biológico, diante de abordagem às lesões ou disfunções orgânicas ${ }^{(25)}$. Dificuldade maior ocorre quando não há marcas visíveis, o que justifica a percepção dos profissionais de saúde de que as situações de violência costumam ser sutis ${ }^{(26)}$.

Esse caráter velado expressa um contexto que requer interesse e sensibilidade profissional no sentido de investigar a relação familiar e conjugal, para afastar a suspeita de violência doméstica. Corroborando, pesquisa em centros de saúde de atenção primária na Espanha destaca o papel fundamental dos profissionais de saúde na identificação da violência conjugal(27). Diante o exposto, é necessária formação em saúde para o reconhecimento e a condução desses casos, sendo os profissionais de enfermagem fundamentais para a identificaçã̃o dos casos de violência, bem como a elaboração de rede de apoio para o enfrentamento da problemática(25,28).

\section{CONSIDERAÇÕES FINAIS}

O estudo revelou que as mulheres entrevistadas vivenciam um cotidiano de violência, expressa nas formas tipificadas pela Lei Maria da Penha: patrimonial, psicológica, moral, sexual e física. Embora o estudo limite-se por investigar apenas uma Vara de Justiça e as características loco-regionais das mulheres da região nordestina, os achados são relevantes no sentido de orientar para o processo de identificação do agravo por parte dos profissionais de saúde.

Assim, a inclusão da temática da violência, com foco nas suas formas de expressão na vida das mulheres, torna-se essencial nos processos formativos, nos âmbitos da educação acadêmica ou continuada de profissionais de saúde, especialmente para a enfermagem. Isso porque ao integrar a equipe de referência na Estratégia Saúde da Família (ESF) e, por vezes, os espaços de coordenação nos serviços de saúde, as enfermeiras encontram-se em posição favorável para a identificação do agravo, primeiro passo para auxiliar a mulher a romper com esta vivência. Para estas ações, cabe ainda a articulação com as esferas da educação, jurídica, policial e social.

No cenário da ESF, os profissionais da saúde podem ainda utilizar-se do conhecimento acerca das expressões da violência conjugal para embasar práticas educativas de mulheres e homens. Desse modo, podem oportunizar espaços de reflexão acerca da construção social de gênero, responsável pela crença do domínio masculino e da subserviência feminina, que sustentam a perpetração da violência conjugal. No contexto da Lei Maria da Penha, que não se limita às ações punitivas como também preventivas, tais espaços são primordiais para que os homens reconheçam o caráter criminoso de suas ações e as mulheres se empoderem, assumindo-se enquanto sujeito de suas vidas. 
1. Nations Unies. Journée internationale pour l'élimination de la violence à l'égard des femmes. New York: Nations Unies; 2015.

2. Waiselfisz JJ. Mapa da violência 2015: homicídios de mulheres no Brasil. Brasília: Flacso; 2015.

3. Brasil. Lei n.11.340, 7 de agosto de 2006. Dispõe sobre a Lei Maria da Penha. Diário Oficial da União, Brasília, 08 ago. 2006.

4. Leite FMC, Santos DF, Castro DS, Albuquerque Netto L, Moura MAV, Lima EFA. The women's perception on the violence experienced. Rev. pesqui. cuid. Fundam. [Internet]. 2017 [acesso em 10 jan 2018]; 9(1). Disponível em: http://dx.doi.org/10.9789/2175-5361.2017.v9i1.193-199.

5. Carneiro JB, Gomes NP, Estrela FM, de Santana JD, Mota RS, Erdmann AL. Domestic violence: repercussions for women and children. Esc. Anna Nery. [Internet]. 2017 [acesso em 21 jan 2018]; 21(4). Disponível em: http://dx.doi.org/10.1590/2177-9465-ean-2016-0346.

6. Wong J, Mellor D. Intimate partner violence and women's health and wellbeing: impacts, risk factors and responses. Contemp Nurse. [Internet]. 2014 [acesso em 21 jan 2018]; 46(2). Disponível em: https:// doi.org/10.5172/conu.2014.46.2.170.

7. Salcedo-Barrientos DM, Miura PO, Macedo VD, Egry EY. How do primary health care professionals deal with pregnant women who are victims of domestic violence? Rev. Latino-Am. Enfermagem. [Internet]. 2014 [acesso em 21 jan 2018]; 22(3). Disponível em: http://dx.doi.org/10.1590/0104-1169.3108.2436.

8. Strauss A, Corbin J. Pesquisa qualitativa: técnicas e procedimentos para o desenvolvimento de teoria fundamentada. Porto Alegre: Artmed; 2008.

9. Sousa AR de, Pereira A, Paixão GPN, Gomes NP, Campos LM, Couto TM. Repercussions of imprisonment for conjugal violence: discourses of men. Rev. Latino-Am. Enfermagem. [Internet]. 2016 [acesso em 28 jan 2018]; 24. Disponível em: http://dx.doi.org/10.1590/1518-8345.1569.2847.

10. Guimaraes MC, Pedroza, RLS. Violência contra a mulher: problematizando definições teóricas, filosóficas e jurídicas. Psicol. Soc. [Internet]. 2015 [acesso em 28 jan 2018]; 27(2). Disponível em: http:// dx.doi.org/10.1590/1807-03102015v27n2p256.

11. Lopes HR, Castro GA de, Pires CLC, Gomes JO de S. Análise do crime de abandono material. Análise do crime de abandono material. Jus [Internet] 2014 [acesso em 24 fev 2018]. Disponível: https://jus.com. br/artigos/32540/analise-do-crime-de-abandono-material.

12. Deere CD, Contreras J, Twyman J. Patrimonial violence: a study of women's property rights in Ecuador. Lat Am Perspect [Internet]. 2013 [acesso em 18 fev 2018]; 41(1). Disponível em: https://doi. org/10.1177/0094582X13492133.

13. Acosta DF, Gomes VLO, Fonseca AD, Gomes GC. Violence Against Women Commited By Intimate Partners: (In) Visibility Of The Problem. Texto context - enferm. [Internet]. 2015 [acesso em 01 mar 2018]; 24(1). Disponível em: http://dx.doi.org/10.1590/0104-07072015001770013.

14. Pereira, RCBR, Loreto, MDS de, Teixeira, KMD, Sousa, JMM de. O fenômeno da violência patrimonial contra as mulheres: percepções das vítimas. Oikos: Rev. Brasileira de Economia Doméstica. [Internet]. 2013 [acesso em 01 mar 2018]; 24(1). Disponível em: http://www.locus.ufv.br/bitstream/ handle/123456789/13801/89-674-2-PB.pdf?sequence=1\&isAllowed=y.

15. Pasinato W. Acesso à justiça e violência doméstica e familiar contra as mulheres: as percepções dos operadores jurídicos e os limites para a aplicação da Lei Maria da Penha. Rev. direito GV. [Internet]. 2015 [acesso em 25 fev 2018]; 11(2). Disponível em: http://dx.doi.org/10.1590/1808-2432201518.

16. Gattegno MV, Wilkins JD, Evans DP. The relationship between the Maria da Penha Law and intimate partner violence in two Brazilian states. Int J Equity Health. [Internet]. 2016 [acesso em 20 fev 2018]; 15(138). Disponível em: https://doi.org/10.1186/s12939-016-0428-3. 
17. Office on Women's Health. Violence against women. Washington: U.S. Department of Health and Human Service; 2015.

18. Piosiadlo LCM, Fonseca RMGS, Gessner R. Subordination of gender: reflecting on the vulnerability to domestic violence against women. Esc. Anna Nery. [Internet]. 2014 [acesso em 05 jan 2018]; 18(4). Disponível em: http://dx.doi.org/10.5935/1414-8145.20140104.

19. Edmunds E, Gupta A. Headline violence and silenced pleasure: contested framings of consensual sex, power and rape in Delhi, India, no período de 2011-2014. Reprod Health Matters. [Internet]. 2016 [acesso em 05 jan 2018]; 24(47). Disponível em: https://doi.org/10.1016/j.rhm.2016.06.004.

20. Hellmann DF, Kinninger MW, Kliem S. Sexual Violence against Women in Germany: Prevalence and Risk Markers. Int J Environ Res Public Health. [Internet]. 2018 [acesso em 15 out 2018]; 15(8). Disponível em: http://doi.org/10.3390/ijerph15081613.

21. Equality Now a just world for women and girls. The world's shame the global rape epidemic how laws around the world are failing to protect women and girls from sexual violence. New York, 2017. Equality Now a just world for women and girls. [acesso em $11 \mathrm{fev}$ 2018]. Disponível em: https://www.equalitynow. org/the global rape epidemic campaign?locale=en.

22. Tiwari A, Cheung DST, Chan KL, Fong DYT, Yan ECW, Lan GLL, et al. Intimate partner sexual aggression against Chinese women: a mixed methods study. BMC Public Health. [Internet]. 2014 [acesso em 11 fev 2018]; 14(70). Disponível em: https://doi.org/10.1186/1472-6874-14-70.

23. Villar AS. Crime de lesão corporal em violência doméstica contra a mulher: a natureza incondicionada da ação penal. Conteúdo Jurídico[Internet]. 2015 [acesso em 28 abr 2018]. Disponível em: http://www. conteudojuridico.com.br/?artigos\&ver=2.54736\&seo=1.

24. Reina AS, Lohman BJ, Maldonado MM. "He said they'd deport me": factors influencing domestic violence help-seeking practices among Latina immigrants. J Interpers Violence. [Internet]. 2014 [acesso em 12 jan 2018]; 29(4). Disponível em: https://www.ncbi.nlm.nih.gov/pubmed/24142446.

25. Gomes NP, Diniz NMF, Reis LA dos, Erdmann AL. The social network for confronting conjugal violence: representations of women who experience this health issue. Texto contexto - enferm [Internet]. 2015 [acesso em 18 fev 2018]; 24(2). Disponível em: http://dx.doi.org/10.1590/010407072015002140012.

26. Vieira EM, Hasse M. Perceptions of professionals in an intersectorial network about the assistance of women in situation of violence. Interface. [Internet]. 2017 [acesso em $01 \mathrm{fev} 2018$ ]; 21(60). Disponível em: https://doi.org/10.1590/1807-57622015.0357.

27. Rodríguez-Blanes GM, Vives-Cases C, Miralles-Bueno JJ, San Sebastián M, Goicolea I. Detection of intimate partner violence in primary care and related factors. Gac Sanit. [Internet]. 2017 [acesso em 22 mar 2018]; 31(5). Disponível em: https://doi.org/10.1016/j.gaceta.2016.11.008.

28. Costa DAC, Marques JF, Moreira KAP, Gomes LFS, Henriques ACPT, Fernandes AFC. Assistência multiprofissional à mulher vítima de violência: atuação de profissionais e dificuldades encontradas. Cogitare enferm. [Internet]. 2013 [acesso em 12 mai 2018]; 18(2). Disponível: http://dx.doi.org/10.5380/ ce.v18i2.29524.

Recebido: 14/05/2018

Finalizado: 18/02/2019

Autor Correspondente:

Nadirlene Pereira Gomes

Universidade Federal da Bahia

R. Dr. Augusto Viana, S/N - 40110-060 - Salvador, BA, Brasil

E-mail: nadirlenegomes@hotmail.com 
Contribuição dos autores:

Contribuições substanciais para a concepção ou desenho do estudo; ou a aquisição, análise ou interpretação de dados do estudo - JBC, NPG, LMC, NPG, KSC, IRV

Elaboração e revisão crítica do conteúdo intelectual do estudo - JBC, NPG, LMC, NPG, KSC, IRV, ALE

Aprovação da versão final do estudo a ser publicado - JBC, NPG, NPG, KSC, IRV, ALE

Responsável por todos os aspectos do estudo, assegurando as questões de precisão ou integridade de qualquer parte do estudo - JBC 